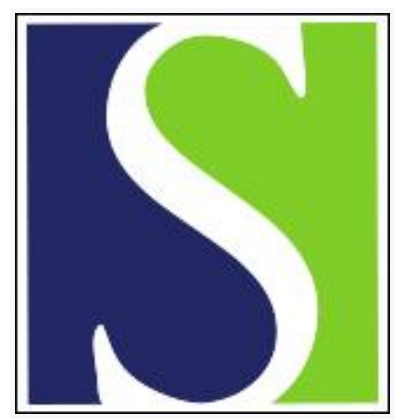

Scand J Work Environ Health 2010;36(2):142-149

https://doi.org/10.5271/sjweh.2893

Published online: 19 Jan 2010, Issue date: 00 Mar 2010

Estimation of the benchmark duration of alternating shift work associated with increased total cholesterol levels among male Japanese workers

by Suwazono Y, Uetani M, Oishi M, Tanaka K, Morimoto H, Nakada S, Sakata K

Affiliation: Department of Occupational and Environmental Medicine, Graduate School of Medicine, Chiba University, Chuoku, Chiba, 260-8670 Japan. suwa@faculty.chiba-u.jp

Refers to the following texts of the Journal: 1988;14(5):317-321 2008;34(1):33-39 2001;27(2):97-105

The following articles refer to this text: $2010 ; 36(2): 81-84$; 2015;41(3):259-267

Key terms: alternating shift work; benchmark; benchmark duration; cholesterol; cholesterol level; circadian rhythm; cohort study; health; health; hypercholesterolemia; Japan; lipid metabolism; male; man; men; shift work; total cholesterol level; worker

This article in PubMed: www.ncbi.nlm.nih.gov/pubmed/20084348

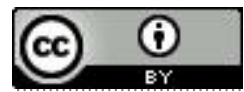




\title{
Estimation of the benchmark duration of alternating shift work associated with increased total cholesterol levels among male Japanese workers
}

\author{
by Yasushi Suwazono, MD, PhD, ${ }^{1,2}$ Mirei Uetani, MD, PhD, ${ }^{1}$ Mitsuhiro Oishi, MD, PhD, ${ }^{1}$ Kumihiko \\ Tanaka, MD, ${ }^{1}$ Hideki Morimoto, MD, ${ }^{1}$ Satoru Nakada, MD, PhD, ${ }^{3}$ Kouichi Sakata, MD, PhD ${ }^{1}$
}

\begin{abstract}
Suwazono Y, Uetani M, Oishi M, Tanaka K, Morimoto H, Nakada S, Sakata K. Estimation of the benchmark duration of alternating shift work associated with increased total cholesterol level among male Japanese workers. Scand J Work Environ Health. 2010;36(2):142-149.
\end{abstract}

\begin{abstract}
Objective The aim of this study was to estimate the benchmark doses (BMD) and their 95\% lower confidence limits (BMDL) for the threshold number of years of alternating shift work associated with a relative increase in serum total cholesterol level (T-Cho), as an index of lipid metabolism.
\end{abstract}

Methods We conducted a 14-year prospective cohort study among male workers $(\mathrm{N}=6886)$ at a Japanese steel company who had received annual health check-ups between 1991 and 2005. The endpoints were either a 20, $25,30,35,40$ or $45 \%$ increase in T-Cho levels during the observation period, compared to T-Cho at baseline. We investigated the associations between the years of alternating shift work and the relative increases in T-Cho using pooled logistic regression, adjusted for other potential covariates.

Results We estimated the BMDL and BMD for years of alternating shift work among 40-, 50-, or $>50$-year old subjects using benchmark responses (BMR) of 5 or $10 \%$ and parameters for the duration of alternating shift work and other covariates. Assuming a mean age of 44 years among workers in their 40s, the BMDL/BMD for years of alternating shift work with a BMR of $5 \%$ were $21.0 / 28.0(\geq 20 \%), 21.3 / 26.1(\geq 25 \%), 24.1 / 28.8(\geq 30 \%)$, 25.6/29.8 ( $\geq 35 \%), 27.1 / 31.5(\geq 40 \%)$, and 27.7/32.1 ( $\geq 45 \%)$.

Conclusions The threshold number of years of alternating shift work that caused a $5 \%$ increase in T-Cho was shown to be $\geq 21$ years among middle-aged workers. Special attention should be paid to influence the process at an earlier stage and not when the risk has already materialized.

Key terms circadian rhythm; cohort study; hypercholesterolemia; lipid metabolism.

Industrialization in Japan and other countries has led to the widespread adoption of 24-hour continuous operations in a number of industries, including the mining, manufacturing, transportation, and service sectors. This has resulted in an increase in the proportion of the population routinely engaged in shift work (1). Therefore, a comprehensive investigation into the health effects of shift work is necessary and urgently required. An association between shift work and cardiovascular diseases has been reported $(2,3)$, with disturbed circadian rhythms, sleep and lifestyle problems, and increased stress implicated as possible mechanisms linking shift work with these diseases. In addition, several cohort studies have reported an association between shift work and the risk of obesity or weight gain $(4,5)$, and the development of the metabolic syndrome $(6,7)$. One potential link between shift work and coronary heart disease may be impaired lipid metabolism. A large body of epidemiological evidence supports a direct relationship between serum total cholesterol (T-Cho) levels and the prevalence of coronary heart disease (8-11). Recently, a meta-analysis of individual data from 61 prospective studies indicated that a decrease in T-Cho levels was associated with lower ischemic heart disease mortality

1 Department of Occupational and Environmental Medicine, Graduate School of Medicine, Chiba University, Chiba, Japan.

2 Center for Preventive Medical Science, Chiba University, Chiba, Japan.

3 Safety and Health Organization, Chiba University, Chiba, Japan.

Correspondence to: Dr Y Suwazono, Department of Occupational and Environmental Medicine, Graduate School of Medicine, Chiba University, 1-8-1, Inohana, Chuoku, Chiba, 260-8670 Japan. [E-mail: suwa@faculty.chiba-u.jp] 
among men and women aged $\geq 40$ years in the majority of developed countries, with no apparent threshold (12). Regarding lipid metabolism, several studies have reported that elevated serum triglyceride (13-15) and lower concentrations of high-density lipoprotein cholesterol $(14,15)$ tend to occur more frequently among shift than fixed daytime workers. It has also been reported that shift work is a significant risk factor for the onset of hypercholesterolemia, although the magnitude of the risk is small (16). A recent longitudinal cohort study confirmed the influence of alternating shift work on increased T-Cho relative to baseline levels (17). However, a dose-response relationship between the duration of alternating shift work and the increase in T-Cho levels has not yet been established.

Several studies have reported that increases in life expectancy, healthier lifestyles, and a global shortage of skilled labor have led to a situation where employees spend more years in the workplace, and as a consequence adaptation of older workers to shift work has attracted international attention $(8,18)$. Costa \& Di Milia (8) showed that aging is associated with greater difficulty in achieving adequate circadian adjustment, due to attenuated responses of the circadian system. It is therefore very important to determine the threshold number of years of shift work that may induce harmful health effects among the older generation.

Following its recent introduction, the benchmark dose (BMD) method has been used increasingly in occupational medicine (19). The BMD is defined as the exposure that corresponds to a specific increase [benchmark response (BMR)] in the probability of an adverse response, compared with background zero exposure. It has been suggested that the lower 95\% confidence limit of the benchmark dose (BMDL) may replace the "no observed adverse effect level" $(20,21)$. One advantage of the BMDL/BMD approach is that it utilizes the whole dose-response curve (20). While the response or risk level at the "no observed adverse effect level" was not assessed and may vary from case to case, the BMDL corresponds to an explicit response level and therefore introduces consistency (22). Using multiple logistic regression, researchers have also shown that it is possible to take into account the effect of potential covariates (23).

The aim of our study was to estimate the BMDL and BMD for the number of years of alternating shift work associated with a relative increase in T-Cho, as an index of lipid metabolism. This was achieved by investigation of the dose-response relationship between the duration of alternating shift work and the increase in T-Cho levels using pooled logistic regression. We used these estimations to determine the permissible threshold number of years people could engage in alternating shift work without increasing their T-Cho level.

\section{Methods}

\section{Subjects}

This prospective cohort study included observations made over a 14-year period from 1991-2005. A total of 6886 subjects (4079 day workers and 2807 alternating shift workers) out of a possible total of 8251 male workers at a Japanese steel company were enrolled in the study. No female employees were engaged in alternating shift work. The cohort consisted of more than $98 \%$ of the workers who attended annual health examinations during the observation period. New participants were enrolled during the follow-up period.

To avoid errors in endpoint determination caused by medication, we excluded subjects treated previously for hypercholesterolemia and classified subjects who began therapy for hypercholesterolemia as censored cases. The following were also excluded from the study: (i) individuals who had a health examination for the first time in the final year (2005) of the follow-up period $(\mathrm{N}=504)$, (ii) those who had pharmacologic therapy initiated for hypercholesterolemia before or in the year of entry to the study $(\mathrm{N}=46)$ or the subsequent year $(\mathrm{N}=21)$, (iii) those with any missing data in the year of entry ( $\mathrm{N}=315)$, (iv) those who did not receive a health examination in the subsequent year $(\mathrm{N}=360)$, and $(\mathrm{v})$ those for whom the measurement of T-Cho was missing in the subsequent year $(\mathrm{N}=119)$.

The type of job schedule (ie, alternating shift or day work) was determined from the corporate pay ledger in May of each year. The shifts were scheduled on a 4-team $/ 3$-shift plan with clockwise rotation (5 day shifts, 2 rest days, 5 evening shifts, 1 rest day, and 5 night shifts and 2 rest days). The day, evening, and night shifts started at 07:00, 15:00 and 23:00 hours, respectively. The percentage of shift workers at study entry who changed their job schedule type during the observation period (maximum: seven times) ranged from $27 \%$ in the cohort with a $\geq 20 \%$ increase in $\mathrm{T}$ Cho to $34 \%$ in the cohort with a $\geq 45 \%$ increase in T-Cho. The percentage of day workers at entry year who changed their job schedule type during the observation period (maximum: seven times) ranged from 16-19\%. Participants who changed from shift to day work were not excluded from the study from that point onwards. The duration of alternating shift work was calculated as the total number of years engaged in this type of work from the entry to each examination year. Therefore, the duration of alternating shift work was not increased when the workers changed from shift to daytime work.

The Ethics Review Board of the Graduate School of Medicine, Chiba University, approved the study protocol. We have no conflicts of interest to declare. 


\section{Measurements}

Data collected at the annual health examination included T-Cho measured by the cholesterol oxidase-peroxidase method [normal: $\leq 220 \mathrm{mg} / \mathrm{dl}(5.7 \mathrm{mmol} / \mathrm{l})]$. The health examinations, including blood sampling, were carried out between 09:00-15:00 hours throughout the study period. No measurements were taken within 30 minutes after eating or heavy physical activity. The medical history of the workers was recorded during the annual health examination using a self-administered questionnaire. These responses were confirmed during individual interviews conducted by occupational physicians.

The endpoints in the study were defined as increases of either $\geq 20, \geq 25, \geq 30, \geq 35, \geq 40$ or $\geq 45 \%$ in $\mathrm{T}$-Cho levels compared to baseline. We measured age, body mass index (BMI), creatinine, glycated hemoglobin $\mathrm{A}_{1 \mathrm{c}}$ $\left(\mathrm{HbA}_{1 \mathrm{c}}\right.$ ), aspartate aminotransferase (AST), $\gamma$-glutamyl transpeptidase (GGT), and uric acid (UA) during the study and, together with drinking, smoking and exercise habits, used them as covariates in the analyses. In order to avoid colinearity in the logistic model, we chose the covariates from the available parameters of the annual health examinations as much as possible, without overlapping with other measurements, such as the markers of liver dysfunction, AST, and alanine aminotransferase.

The measurements were conducted in comprehensive clinical testing laboratories that met the requirements of official certification organizations. Information on drinking, smoking exercise habits was obtained from self-administered questionnaires carried out at the annual health examination. The workers were asked to identify themselves as either (i) "smokers" or "nonsmokers", (ii) "drinking every day" or "not drinking every day", and (iii) "exercising regularly" or "not exercising regularly".

\section{Statistical analysis}

We used pooled logistic regression analysis to evaluate the effect of the duration of alternating shift work on each of the six T-Cho endpoints measured annually. These endpoints were adjusted for annually updated: age; BMI; creatinine; $\mathrm{HbA}_{1 c}$; AST; GGT; UA; and drinking, smoking, and exercise habits; in addition to T-Cho level at entry to the study. All the covariates were included simultaneously in the statistical model. As the data on baseline T-Cho, creatinine, $\mathrm{HbA}_{1 c}$, AST, GGT, and UA were not normally distributed, we used a base of 1.1 to logarithmically transform the values. This transformation resulted in a $10 \%$ increase in the odds ratio (OR) for the variables.

In our previous report, we described pooled logistic regression analysis in detail (17). Each examination interval of one year was treated as a mini follow-up study and, therefore, the method included the concept of person-years. Using this method, we adjusted the derived OR of the endpoints for the effects of other time-variable covariates (24). The number of years of alternating shift work was used as the continuous variable to estimate the BMDL and BMD. The BMDL and BMD were adjusted for the effects of the other covariates using parameters obtained by pooled logistic regression. The BMD concept was introduced by Crump (21) and involves fitting a mathematical model to dose-response data. The BMD is defined as the dose that causes a predetermined change in response (22). This specified change in response is generally referred to as the BMR (22). The detailed method for estimating BMD is described in a previous report (19). The BMD was calculated using the following equation:

$\mathrm{BMD}=\frac{1}{\beta} \operatorname{In} \frac{[P(0)+\mathrm{BMR}] \times[1-P(0)]}{[1-P(0)-\mathrm{BMR}] \times[P(0)]}$ equation 1

where $P(0)=$ the background probability of an adverse response at the alternating shift work duration $=0$ years; $\mathrm{BMR}=$ an additional pre-specified increase in the probability of a positive finding $(5 \%$ or $10 \%)$ and $\beta=$ the slope for alternating shift work period in years-log odds relationship. BMDL and BMD were calculated for each endpoint only when the $\beta$ value obtained for the alternating shift work period was significant. In order to estimate BMDL and BMD among subjects $\geq 40$ years, we assumed the covariates to be non-drinking, non-smoking, habitual exercise, mean age, mean BMI, and the geometric means of baseline T-Cho, creatinine, $\mathrm{HBA}_{1 \mathrm{c}}$, AST, GGT, and UA among the 40-49- and $\geq 50$-year old age groups. The BMDL is defined as the one-sided lower $95 \%$ confidence limit $(95 \% \mathrm{CL}$ ) of the BMD (22). We used the profile likelihood method $(21,25)$ to calculate the BMDL.

The analyses were performed with SPSS 12.0.1 J software (SPSS Japan Inc, Tokyo, Japan) and Microsoft Excel (BMDL estimation, Microsoft Corporation, Redmond, WA, USA). A P-value of $<0.05$ was considered to be statistically significant.

\section{Results}

Table 1 summarizes the characteristics of the subjects at entry year of the study, grouped according to age. T-Cho, BMI, and $\mathrm{HbA}_{1 \mathrm{c}}$ were higher among older workers, while the percentage of subjects who drank every day or who did not exercise regularly was lower among younger workers. As the majority of newly-hired employees were highschool graduates under the legal drinking age of 20 years, only $10.1 \%$ of young workers 
Table 1. Characteristics of the subjects at year of entry to the study, grouped according to age at entry. [BMI = body mass index; T-Cho= serum total cholesterol; $\mathrm{HbA}_{1 \mathrm{c}}=$ glycated hemoglobin $\mathrm{A}_{1 \mathrm{c}}$; $\mathrm{AST}=$ aspartate aminotransferase; $\mathrm{GGT}=\gamma$-glutamyl transpeptidase; UA= uric acid; $\mathrm{SD}=$ standard deviation; Geom mean = geometric mean]

\begin{tabular}{|c|c|c|c|c|c|c|c|c|c|c|c|c|c|c|c|c|c|c|c|c|}
\hline \multirow[t]{2}{*}{$\begin{array}{l}\text { Age } \\
\text { (years) }\end{array}$} & \multicolumn{2}{|c|}{$\begin{array}{c}\text { Age } \\
\text { (years) }\end{array}$} & \multicolumn{2}{|c|}{$\begin{array}{c}\text { BMI } \\
\left(\mathrm{kg} / \mathrm{m}^{2}\right)\end{array}$} & \multicolumn{2}{|c|}{$\begin{array}{c}\text { T-Cho } \\
(\mathrm{mmol} / \mathrm{l})\end{array}$} & \multicolumn{2}{|c|}{$\begin{array}{c}\text { Creatinine } \\
(\mu \mathrm{mol} / \mathrm{l})\end{array}$} & \multicolumn{2}{|c|}{$\begin{array}{c}\mathrm{HbA}_{1 \mathrm{c}} \\
(\%)\end{array}$} & \multicolumn{2}{|c|}{$\begin{array}{l}\text { AST } \\
(\mathrm{IU} / \mathrm{l})\end{array}$} & \multicolumn{2}{|c|}{$\begin{array}{l}\text { GGT } \\
(\mathrm{IU} / \mathrm{I})\end{array}$} & \multicolumn{2}{|c|}{$\begin{array}{c}U A \\
(\mu \mathrm{mol} / \mathrm{l})\end{array}$} & \multirow{2}{*}{$\begin{array}{c}\text { Job } \\
\text { sched- } \\
\text { ule } \\
\text { type }{ }^{a} \\
(\%)\end{array}$} & \multirow{2}{*}{$\begin{array}{l}\text { Drink- } \\
\text { ing } \\
\text { habit }^{b} \\
(\%)\end{array}$} & \multirow{2}{*}{$\begin{array}{c}\text { Smok- } \\
\text { ing } \\
\text { habitc } \\
(\%)\end{array}$} & \multirow{2}{*}{$\begin{array}{c}\text { Habi- } \\
\text { tual } \\
\text { exer- } \\
\text { cised }^{\mathrm{d}} \\
(\%)\end{array}$} \\
\hline & Mean & SD & Mean & SD & $\begin{array}{l}\text { Geom } \\
\text { mean }\end{array}$ & SD & $\begin{array}{l}\text { Geom } \\
\text { mean }\end{array}$ & SD & $\begin{array}{l}\text { Geom } \\
\text { mean }\end{array}$ & SD & $\begin{array}{l}\text { Geom } \\
\text { mean }\end{array}$ & SD & $\begin{array}{l}\text { Geom } \\
\text { mean }\end{array}$ & SD & $\begin{array}{l}\text { Geom } \\
\text { mean }\end{array}$ & SD & & & & \\
\hline $\begin{array}{l}<30 \\
(N=1806)\end{array}$ & 22.3 & 3.6 & 22.6 & 3.3 & 4.28 & 0.03 & 77.0 & 103.1 & 4.5 & 1.1 & 18.2 & 1.4 & 14.2 & 1.7 & 329 & 73 & 33.7 & 10.1 & 59.7 & 36.7 \\
\hline $\begin{array}{l}30-39 \\
(N=2138)\end{array}$ & 35.8 & 2.6 & 23.6 & 2.8 & 4.87 & 0.03 & 77.3 & 106.1 & 4.6 & 1.1 & 21.4 & 1.4 & 26.2 & 2.1 & 329 & 76 & 43.3 & 51.9 & 66.7 & 45.3 \\
\hline $\begin{array}{l}40-49 \\
(\mathrm{~N}=2400)\end{array}$ & 44.1 & 3.0 & 23.7 & 2.7 & 5.01 & 0.03 & 77.5 & 105.6 & 4.7 & 1.1 & 21.8 & 1.4 & 28.1 & 2.2 & 324 & 76 & 47.7 & 54.0 & 62.0 & 48.4 \\
\hline $\begin{array}{l}\geq 50 \\
(N=542)\end{array}$ & 53.0 & 2.7 & 24.0 & 2.7 & 5.16 & 0.03 & 74.8 & 109.1 & 5.1 & 1.1 & 21.6 & 1.4 & 27.7 & 2.1 & 331 & 76 & 23.6 & 48.2 & 48.5 & 46.3 \\
\hline
\end{tabular}

a Alternating shift work.

${ }^{\mathrm{b}}$ Everyday.

c Smoker.

${ }^{\mathrm{d}}$ No.

Table 2. Number of person-years studied and incidence rate for relative increases in total cholesterol level versus level at entry to the study, grouped according to age at entry. [Obs=0bservation; IR=incidence rate]

\begin{tabular}{|c|c|c|c|c|c|c|c|c|c|c|c|c|c|c|c|c|c|c|}
\hline \multirow{3}{*}{$\begin{array}{l}\text { Age } \\
\text { (years) }\end{array}$} & \multicolumn{18}{|c|}{ Increase by } \\
\hline & \multicolumn{3}{|c|}{$\geq 20 \%$} & \multicolumn{3}{|c|}{$\geq 25 \%$} & \multicolumn{3}{|c|}{$\geq 30 \%$} & \multicolumn{3}{|c|}{$\geq 35 \%$} & \multicolumn{3}{|c|}{$\geq 40 \%$} & \multicolumn{3}{|c|}{$\geq 45 \%$} \\
\hline & Obs ${ }^{a}$ & $\mathrm{IR}^{\mathrm{b}}$ & Mean c & Obs ${ }^{a}$ & $\mathrm{IR}^{\mathrm{b}}$ & Mean ${ }^{c}$ & Obs ${ }^{a}$ & $\mathrm{IR}^{\mathrm{b}}$ & Mean $^{c}$ & Obs ${ }^{a}$ & $\mathrm{IR}^{\mathrm{b}}$ & Mean ${ }^{c}$ & Obs ${ }^{a}$ & $\mathrm{IR}^{\mathrm{b}}$ & Mean $^{c}$ & Obs ${ }^{a}$ & $\mathrm{IR}^{\mathrm{b}}$ & Mean ${ }^{c}$ \\
\hline$<30$ & 8901 & 86.5 & 4.93 & 10034 & 54.8 & 5.56 & 10865 & 35.7 & 6.02 & 11441 & 22.9 & 6.33 & 11743 & 14.6 & 6.50 & 11963 & 10.2 & 6.62 \\
\hline 30-40 & 15970 & 55.9 & 7.47 & 17887 & 34.4 & 8.37 & 19308 & 20.9 & 9.03 & 20184 & 12.6 & 9.44 & 20684 & 7.3 & 9.67 & 20945 & 4.4 & 9.80 \\
\hline $40-50$ & 17747 & 45.7 & 7.39 & 19504 & 26.5 & 8.13 & 20705 & 14.9 & 8.63 & 21355 & 8.2 & 8.90 & 21740 & 4.9 & 9.06 & 21958 & 2.6 & 9.15 \\
\hline$>50$ & 1930 & 44.0 & 3.56 & 2037 & 24.5 & 3.76 & 2120 & 11.8 & 3.91 & 2154 & 6.0 & 3.97 & 2161 & 4.2 & 3.99 & 2169 & 2.3 & 4.00 \\
\hline Total & 44548 & 57.4 & 6.47 & 49462 & 35.0 & 7.18 & 52998 & 21.2 & 7.70 & 55134 & 12.8 & 8.01 & 56328 & 7.8 & 8.18 & 57035 & 4.8 & 8.28 \\
\hline
\end{tabular}

a Total person-years.

${ }^{\mathrm{b}}$ Per 1000-person years.

c Observed years per person.

drank alcohol every day. Table 2 shows the number of person-years studied and the incidence rate of changes in T-Cho levels. The incidence rates per 1000 person-years were 57.4 ( $\geq 20 \%$ increase in T-Cho level), 35.0 ( $\geq 25 \%$ increase), 21.2 ( $\geq 30 \%$ increase), 12.8 ( $\geq 35 \%$ increase), 7.8 ( $\geq 40 \%$ increase), and 4.8 ( $\geq 45 \%$ increase).

Table 3 shows the OR and $95 \%$ confidence intervals $(95 \% \mathrm{CI})$ of the duration of alternating shift work in years associated with increases in T-Cho level, compared to levels at study entry. The duration of alternating shift work in years was associated significantly with all six T-Cho endpoints [ $\geq 20 \%$, OR $1.03(95 \% \mathrm{CI}$ $1.02-1.04) ; \geq 25 \%$, OR 1.05 (95\% CI $1.03-1.06$ ); $\geq 30 \%$, OR 1.06 (95\% CI $1.04-1.08)$; $\geq 35 \%$, OR 1.09 (95\% CI $1.06-1.11)$; $\geq 40 \%$, OR 1.10 (95\% CI 1.08-1.13); $\geq 45 \%$, OR 1.13 (95\% CI 1.09-1.16)]. Generally, the OR of the duration of alternating shift work tended to be higher for greater relative increases in the T-Cho level, suggesting the stronger association for a more serious outcome. There was a positive association between GGT and all six T-Cho endpoints, while T-Cho at entry to the study was associated negatively with all six endpoints. Multiple significant OR were obtained for (i) BMI (positive: $25 \%, 30 \% 35 \%, 40 \%$, and $45 \%$ ), (ii) $\mathrm{HbA}_{1 \mathrm{c}}$ (positive: $25 \%, 30 \% 35 \%, 40 \%$, and $45 \%$ ), (iii) age (negative: $35 \%$ and $45 \%$ ), and (iv) drinking habit (negative: $20 \%$ and $25 \%$ ). No consistent relationship was observed for creatinine, AST, UA, smoking, or exercise habits.

Table 4 shows the BMDL and BMD for years of alternating shift work that induced relative increases in T-Cho level compared to the level at study entry. The estimated BMDL among workers in their 40s ranged between 21.0-33.5 years and the estimated BMD 
Table 3. Odds ratios $(\mathrm{OR})$ and $95 \%$ confidence intervals $(95 \% \mathrm{Cl})$ for relative increases in serum total cholesterol (T-Cho) level versus level at study entry. The data of T-Cho at baseline, creatinine, glycated hemoglobin $\mathrm{A}_{1 \mathrm{c}}\left(\mathrm{HbA}_{1 \mathrm{c}}\right.$ ), aspartate aminotransferase (AST), $\gamma$-glutamyl transpeptidase (GGT), and uric acid (UA) were logarithmically transformed using a base of 1.1. The alternating shift work period was calculated as the total number of years engaged in alternating shift work from entry year to each examination year. [BMI = body mass index]

\begin{tabular}{|c|c|c|c|c|c|c|c|c|c|c|c|c|c|c|c|c|c|c|}
\hline & \multicolumn{18}{|c|}{ Increase by } \\
\hline & \multicolumn{3}{|c|}{$\geq 20 \%$} & \multicolumn{3}{|c|}{$\geq 25 \%$} & \multicolumn{3}{|c|}{$\geq 30 \%$} & \multicolumn{3}{|c|}{$\geq 35 \%$} & \multicolumn{3}{|c|}{$\geq 40 \%$} & \multicolumn{3}{|c|}{$\geq 45 \%$} \\
\hline & $O R^{a}$ & $95 \% \mathrm{Cl}$ & $\begin{array}{c}\mathrm{P}- \\
\text { value }\end{array}$ & $\mathrm{OR}^{\mathrm{a}}$ & $95 \% \mathrm{Cl}$ & $\begin{array}{c}\mathrm{P}- \\
\text { value }\end{array}$ & $\mathrm{OR}^{\mathrm{a}}$ & $95 \% \mathrm{Cl}$ & $\begin{array}{c}\mathrm{P}- \\
\text { value }\end{array}$ & $\mathrm{OR}^{\mathrm{a}}$ & $95 \% \mathrm{Cl}$ & $\begin{array}{c}\mathrm{P}- \\
\text { value }\end{array}$ & $\mathrm{OR}^{\mathrm{a}}$ & $95 \% \mathrm{Cl}$ & $\begin{array}{c}\mathrm{P}- \\
\text { value }\end{array}$ & $O R^{a}$ & $95 \% \mathrm{Cl}$ & $\begin{array}{c}\mathrm{P}- \\
\text { value }\end{array}$ \\
\hline $\begin{array}{l}\text { Alternating } \\
\text { shift work } \\
\text { period } \\
\text { (years) }\end{array}$ & 1.03 & $1.02-1.04$ & 0.000 & 1.05 & $1.03-1.06$ & 0.000 & 1.06 & $1.04-1.08$ & 0.000 & 1.09 & $1.06-1.11$ & 0.000 & 1.10 & $1.08-1.13$ & 0.000 & 1.13 & $1.09-1.16$ & 0.000 \\
\hline $\begin{array}{l}\text { T-Cho b } \\
(\mathrm{mmol} / \mathrm{l})\end{array}$ & 0.67 & $0.65-0.69$ & 0.000 & 0.63 & $0.62-0.65$ & 0.000 & 0.62 & $0.59-0.64$ & 0.000 & 0.57 & $0.55-0.60$ & 0.000 & 0.55 & $0.52-0.58$ & 0.000 & 0.54 & $0.51-0.58$ & 0.000 \\
\hline Age (year) & 1.00 & $0.99-1.00$ & 0.151 & 1.00 & $0.99-1.00$ & 0.279 & 0.99 & $0.99-1.00$ & 0.059 & 0.99 & $0.98-1.00$ & 0.019 & 0.99 & $0.98-1.00$ & 0.065 & 0.98 & $0.97-0.99$ & 0.004 \\
\hline $\mathrm{BMI}\left(\mathrm{kg} / \mathrm{m}^{2}\right)$ & 1.01 & $1.00-1.03$ & 0.066 & 1.03 & $1.01-1.05$ & 0.001 & 1.05 & $1.03-1.08$ & 0.000 & 1.07 & $1.04-1.10$ & 0.000 & 1.10 & $1.06-1.13$ & 0.000 & 1.10 & $1.05-1.14$ & 0.000 \\
\hline $\begin{array}{l}\text { Creatinine } \\
(\mu \mathrm{mol} / \mathrm{l})\end{array}$ & 0.99 & $0.97-1.02$ & 0.531 & 0.99 & $0.96-1.02$ & 0.428 & 0.99 & $0.96-1.03$ & 0.661 & 1.00 & $0.95-1.04$ & 0.885 & 0.99 & $0.94-1.05$ & 0.753 & 1.00 & $0.93-1.08$ & 0.959 \\
\hline $\mathrm{HbA}_{1 \mathrm{c}}(\%)$ & 1.03 & $0.99-1.07$ & 0.138 & 1.06 & $1.01-1.11$ & 0.011 & 1.08 & $1.02-1.14$ & 0.006 & 1.11 & $1.04-1.19$ & 0.003 & 1.15 & $1.05-1.25$ & 0.002 & 1.13 & $1.01-1.27$ & 0.034 \\
\hline AST (IU/I) & 1.01 & $0.99-1.02$ & 0.259 & 1.01 & $1.00-1.03$ & 0.081 & 1.02 & $1.00-1.04$ & 0.067 & 1.02 & $0.99-1.04$ & 0.125 & 1.03 & $1.00-1.06$ & 0.029 & 1.03 & $0.99-1.07$ & 0.137 \\
\hline GGT (IU/I) & 1.02 & $1.01-1.03$ & 0.000 & 1.02 & $1.01-1.03$ & 0.000 & 1.03 & $1.01-1.04$ & 0.000 & 1.03 & $1.02-1.05$ & 0.000 & 1.03 & $1.01-1.05$ & 0.000 & 1.03 & $1.01-1.05$ & 0.003 \\
\hline $\mathrm{UA}(\mu \mathrm{mol} / \mathrm{l})$ & 0.99 & $0.97-1.01$ & 0.176 & 1.00 & $0.98-1.02$ & 0.991 & 1.00 & $0.97-1.03$ & 0.973 & 1.00 & $0.97-1.03$ & 0.874 & 1.00 & $0.96-1.05$ & 0.862 & 1.03 & $0.98-1.09$ & 0.298 \\
\hline $\begin{array}{l}\text { Drinking } \\
\text { habitc }^{c}\end{array}$ & 0.87 & $0.79-0.96$ & 0.003 & 0.85 & $0.76-0.95$ & 0.005 & 0.89 & $0.78-1.02$ & 0.098 & 0.87 & $0.74-1.04$ & 0.124 & 0.94 & $0.76-1.17$ & 0.590 & 1.11 & $0.84-1.46$ & 0.464 \\
\hline $\begin{array}{l}\text { Smoking } \\
\text { habit }^{d}\end{array}$ & 1.02 & $0.94-1.11$ & 0.618 & 1.01 & $0.91-1.12$ & 0.861 & 1.03 & $0.90-1.17$ & 0.679 & 1.04 & $0.88-1.22$ & 0.630 & 1.01 & $0.82-1.24$ & 0.939 & 0.94 & $0.73-1.22$ & 0.650 \\
\hline $\begin{array}{l}\text { Habitual } \\
\text { exercise }{ }^{e}\end{array}$ & 0.97 & $0.90-1.06$ & 0.538 & 0.90 & $0.81-0.99$ & 0.037 & 0.89 & $0.79-1.01$ & 0.074 & 1.00 & $0.86-1.16$ & 0.988 & 0.91 & $0.75-1.10$ & 0.336 & 1.01 & $0.79-1.29$ & 0.924 \\
\hline
\end{tabular}

a Adjusted for the effect of all other covariates, with the ratio of the former to the latter being estimated for drinking habits, smoking habits and habitual exercise using pooled logistic regression.

${ }^{\mathrm{b}}$ At entry to the study.

c Everyday/not everyday.

d Smoker/non-smoker.

${ }^{\text {e }}$ No/yes.

between 26.1-44.4 years. The estimated BMDL in workers aged $\geq 50$ years ranged between $22.7-35.6$ years and the estimated BMD between 27.8-47.5 years.

\section{Discussion}

To our knowledge, this is the first study that has used pooled logistic regression to estimate the BMDL and BMD for years of alternating shift work associated with an increase in T-Cho levels. The results of our study provide actual information on the allowable number of years that alternating shift work may be undertaken. This is a notable advantage for controlling the risk associated with alternating shift work compared to previous studies that reported only the relative risk for shift compared to day work. The majority of workers employed by the company investigated in our study started work at 18 years of age, with educational levels being very similar between day and alternating shift workers and the majority of workers being highschool graduates. Very few university graduates were engaged in daytime work.

For workers in their 40 s, the lowest BMDL that represented the threshold number of years of alternating shift work were estimated to be approximately 20 years $(20 \%, 25 \%$, and $30 \%$ increase, $5 \%$ BMR). These results indicate the earliest effect of continuing alternating shift work on T-Cho level is likely to occur when the workers are in their 40s. On the other hand, the BMDL for a $10 \%$ BMR were estimated to be $>30$ years. However, workers in their 40s, who had engaged in alternating shift work for $30-40$ years, were unlikely to exist. Therefore, it is not likely that such a large increase in the probability of impaired lipid metabolism exists in alternating shift workers in their 40s.

On the other hand, for workers aged $\geq 50$ years, the lowest BMDL for years of alternating shift work were estimated to be $23-26$ years $(20 \%, 25 \%$, and $30 \%$ increases, $5 \%$ BMR). These results indicate the early effect of cumulative alternating shift work on T-Cho 
Table 4. Benchmark duration of years of alternating shift work associated with relative increases in total cholesterol level versus level at entry to the study assuming the workers were $40-49$ or $\geq 50$ years. [BMDL $=$ lower $95 \%$ confidence limit of benchmark dose; $B M D=$ benchmark dose; BMR = benchmark response.]

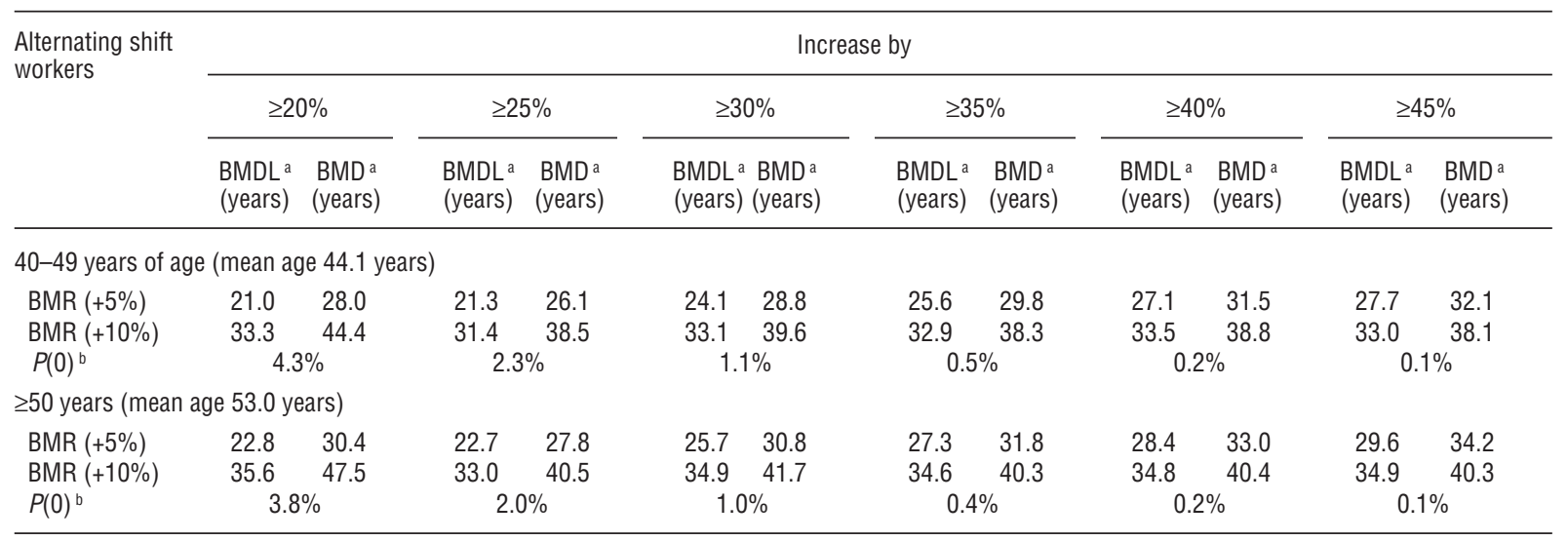

${ }^{a}$ Calculated assuming non-drinking, non-smoking, habitual exercise, mean age, mean body mass index and geometric means of total cholesterol at entry to the study, creatinine, glycated hemoglobin $A_{1 c}$, aspartate aminotransferase, $\gamma$-glutamyl transpeptidase, and uric acid in workers aged in their 40 s or $\geq 50$ years as shown in table 1.

${ }^{b}$ Background probability of adverse response for the alternating shift work period $=0$ years

levels may occur in workers $>50$ years of age, even if they had not been engaged in alternating shift work for their entire working life. Furthermore, the largest BMDL for workers aged $>50$ years was estimated to $\leq 36$ years. Consequently, assuming a mean age of 53.0 years, workers who had engaged continuously in alternating shift work after graduating from highschool may have already exceeded most of the BMDL estimated in the present study. This raises significant concerns about the increased risk of impaired lipid metabolism among continuous alternating shift workers aged $>50$ years.

In this study, we used pooled logistic regression analyses in which each annual examination was treated as a mini follow-up study. This type of analysis is equivalent to a Cox time-dependent regression analysis (24). The strength of this method is that the BMDL and BMD obtained are adjusted for many potential covariates in the multivariate model, which consequently are updated at each annual examination. As noted above, fluctuations in the type of job schedule occurred according to the actual production status of the company. However, the apparent effects of these fluctuations on the results were adjusted more adequately by this method compared to a statistical model that included only the baseline job schedule type. Furthermore, the endpoints in the study were defined as different levels of T-Cho increase, relative to values measured on entry to the study. This differs from a previous study (16) in which the endpoints were defined as a T-Cho that exceeded a certain value, such as $220 \mathrm{mg} / \mathrm{dl}(5.7 \mathrm{mmol} / \mathrm{l})$. The endpoints we used in our study, therefore, prevented bias resulting from the exclusion of subjects whose baseline T-Cho exceeded the ordinal definition of the endpoint. In addition, we believe the endpoints in our study could detect a subclinical effect of alternating shift work on T-Cho, which was not detected by the adverse response with clinical rationale in the previous study (16). From the viewpoint of preventive medicine, it is important to detect subclinical as well as clinical changes in T-Cho. Therefore, the results of our study complement the results of the previous study (16) with respect to the establishment of the effect of alternating shift work on T-Cho. On the other hand, the results of our study do not provide definite clinical proof that workers whose duration of alternating shift work was higher than the BMDL should stop alternating shift work. In relation to the type of job, Bøggild et al (26) found that, in a random sample of Danish employees, shift workers more often than their daytime counterparts reported a higher exposure to an unfavorable work environment that may act as a confounder. However, because all subjects in our study were employed by a large company in Japan, their working environments were equally maintained. The efforts of employers in such companies to protect workers from harmful work environments generally exceed the requirements of the Industrial Safety and Health Law. In 2002, we administered an extensive questionnaire (27) and found $90 \%$ of alternating shift workers to be onsite versus $40 \%$ of day workers. Of the day workers, $20 \%$ were engaged in office work and $22 \%$ in research and technical work. In this company, onsite workers are engaged in activities related to steel production and equipment maintenance and usually monitor and operate the production process remotely in a safe and comfortable operations room, without the demands of heavy physical labor. Occasionally these workers enter the production site to carry out equipment maintenance whilst the production process is suspended. 
Consequently, we did not consider work type to be a major confounding factor in our study. Nevertheless, it is necessary to be careful when generalizing our findings on male Japanese workers from one large plant. In Japan, employers are required to provide shift workers with a health examination twice a year. Furthermore, full-time occupational physicians were employed to provide high-quality and equal occupational health services for all workers in this steel plant. Therefore, differences in working environment, gender, and ethnicity may yield different threshold durations of alternating shift work.

There are several potential limitations of our study that require comment. One concern is the fact that the dichotomized dependent variable was unable to identify decreases in T-Cho level lower than the endpoint, a feature common in the earlier study discussed above (16). The relevance of T-Cho as a marker of lipid metabolism was indicated at the beginning of this study (10). Thereafter, accumulated epidemiological evidence demonstrated that triglycerides are, in fact, an independent risk factor for coronary heart disease (9). On the other hand, high and low density lipoprotein (HDL and LDL) cholesterol substituted for T-Cho, because of their spread of measurement and effectiveness as a marker of lipid metabolism (9). Therefore, HDL cholesterol, as well as triglyceride, have been included in the criteria for the metabolic syndrome instead of T-Cho (28). As a consequence, we believe T-Cho may be replaced by HDL and LDL cholesterol, but not triglyceride. Furthermore, T-Cho can be measured at any time of day in a non-fasting state $(9$, 10 ), as T-Cho does not change appreciably after a meal containing fat. Therefore, we used T-Cho in our study.

Another limitation was that we were unable to investigate other factors in detail, such as lifestyle, type of work, eating habits, and socioeconomic status during all the follow-up periods. The measures of drinking habits and physical activity were crude and used a yes/ no format, which may not have accounted for detailed differences in these lifestyle habits. However, BMI and a variety of biological data were included in the model as covariates, with these variables also reflecting the effects of various lifestyles, especially in healthy subjects. We therefore believe the data on BMI and other biological characteristics may complement our data on self-reported lifestyle-related factors. In regards to these covariates, we estimated the OR without adjusting for BMI, drinking, and smoking, and exercise habits. This approach clarified the consequences of adjusting for these variables as they may be an effect of lifestylerelated problems due to shift work. As a result, the OR without adjustment for these covariates had similar, but slightly decreased significance compared to the fully adjusted OR. Therefore, we believe adjusting for these covariates enabled us to obtain more accurate BMDL.
A final limitation to point out was that the number of years the subjects had been working prior to entering the study (either as day or alternating shift workers) was not determined during the observation period of the study. The majority of person-years was observed in participants who were aged $\geq 30$ years (ie, $\geq 12$ years of working experience). It is likely the duration of alternating shift work before the study may have had some effect on the study outcomes. As the number of these years was not determined in the study, the lack of adjustment for this effect should be taken into account. However, we consider that the T-Cho level at entry into the study to some extent reflects this pre-study effect. Therefore, the relative increase in T-Cho after entry may adequately reflect the effect of the additional exposure to alternating shift work. Furthermore, although we could not determine the direction of the bias, we consider the inclusion in the statistical model of T-Cho levels at study entry, may to some extent reflect the effects that had occurred prior to the study.

In summary, our findings show the threshold number of years of alternating shift work that induces impaired lipid metabolism to be $\geq 21$ years among middle-aged workers. These results suggest that special attention should be paid to middle-aged workers whose duration of alternating shift work exceeds this threshold value. Efficient health screening and regular checkups, combined with support to control unhealthy lifestyle factors, may be of considerable benefit in influencing the process at an earlier stage and not when risk has already materialized. Furthermore, the benchmark duration of alternating shift work for weight gain or $\mathrm{HbA}_{1 \mathrm{c}}$ should be investigated in order to accumulate scientific knowledge on the health effects of shift work duration.

\section{Acknowledgements}

This study was supported by a grant from the Japan Society for the Promotion of Science (Grants-in-Aid for Scientific Research, (C) no. 17590508).

\section{References}

1. Ministry of Health, Labour and Welfare. General survey on working conditions in 2005. Tokyo: Ministry of Health, Labour and Welfare; 2005.

2. Knutsson A, Bøggild H. Shiftwork and cardiovascular disease: review of disease mechanisms. Rev Environ Health. 2000;15:359-72.

3. Knutsson A. Health disorders of shift workers. Occup Med (Lond). 2003;53:103-8. 
4. Niedhammer I, Lert F, Marne MJ. Prevalence of overweight and weight gain in relation to night work in a nurses' cohort. Int J Obes Relat Metab Disord. 1996;20:625-33.

5. Suwazono Y, Dochi M, Sakata K, Okubo Y, Oishi M, Tanaka $\mathrm{K}$, et al. A longitudinal study on the effect of shift work on weight gain in male Japanese workers. Obesity (Silver Spring). 2008;16:1887-93.

6. Esquirol Y, Bongard V, Mabile L, Jonnier B, Soulat JM, Perret B. Shift work and metabolic syndrome: respective impacts of job strain, physical activity, and dietary rhythms. Chronobiol Int. 2009;26:544-59.

7. Lin YC, Hsiao TJ, Chen PC. Persistent rotating shift-work exposure accelerates development of metabolic syndrome among middle-aged female employees: a five-year follow-up. Chronobiol Int. 2009;26:740-55.

8. Grundy SM, Cleeman JI, Daniels SR, Donato KA, Eckel RH, Franklin BA, et al. Diagnosis and management of the metabolic syndrome: an American Heart Association/National Heart, Lung, and Blood Institute Scientific Statement. Circulation. 2005; 112:2735-52.

9. National Cholesterol Education Program Expert Panel. Third Report of the National Cholesterol Education Program (NCEP) Expert Panel on Detection, Evaluation, and Treatment of High Blood Cholesterol in Adults (Adult Treatment Panel III) final report. Circulation. 2002;106:3143-421.

10. National Cholesterol Education Program Expert Panel. Report of the National Cholesterol Education Program Expert Panel on Detection, Evaluation, and Treatment of High Blood Cholesterol in Adults: The Expert Panel. Arch Intern Med. 1988;148:36-69.

11. Hulley SB, Rhoads GG. The plasma lipoproteins as risk factors: comparison of electrophoretic and ultracentrifugation results. Metabolism. 1982;31:773-7.

12. Lewington S, Whitlock G, Clarke R, Sherliker P, Emberson $\mathrm{J}$, Halsey J, et al. Blood cholesterol and vascular mortality by age, sex, and blood pressure: a meta-analysis of individual data from 61 prospective studies with 55,000 vascular deaths. Lancet. 2007;370:1829-39.

13. Knutsson A, Åkerstedt T, Jonsson BG. Prevalence of risk factors for coronary artery disease among day and shift workers. Scand J Work Environ Health. 1988;14:317-21.

14. Karlsson B, Knutsson A, Lindahl B. Is there an association between shift work and having a metabolic syndrome? Results from a population based study of 27,485 people. Occup Environ Med. 2001;58:747-52.

15. Karlsson BH, Knutsson AK, Lindahl BO, Alfredsson LS. Metabolic disturbances in male workers with rotating threeshift work: results of the WOLF study. Int Arch Occup Environ Health. 2003;76:424-30.
16. Dochi M, Sakata K, Oishi M, Tanaka K, Kobayashi E, Suwazono Y. Relationship between shift work and hypercholesterolemia in Japan. Scand J Work Environ Health. 2008;34(1):33-9.

17. Dochi M, Suwazono Y, Sakata K, Okubo Y, Oishi M, Tanaka K, et al. Shift work is a risk factor for increased total cholesterol level: a 14-year prospective cohort study on 6886 male workers. Occup Environ Med. 2009;66:592-7.

18. Bohle P, Di Milia L, Fletcher A, Rajaratnam S. Introduction: aging and the multifaceted influences on adaptation to working time. Chronobiol Int. 2008;25:155-64.

19. Suwazono Y, Sakata K, Harada H, Oishi M, Okubo Y, Uetani $\mathrm{M}$, et al. Benchmark dose of working hours in relation to subjective fatigue symptoms in Japanese male workers. Ann Epidemiol. 2006;16:726-32.

20. US Environmental Protection Agency (US EPA). 2. Background. The Use of the Benchmark Dose (BMD) Approach in Health Risk Assessment Final report. Washington (DC): Risk Assessment Forum, US EPA; 1995

21. Crump KS. A new method for determining allowable daily intakes. Fundam Appl Toxicol. 1984;4:854-71.

22. Sand S, Victorin K, Filipsson AF. The current state of knowledge on the use of the benchmark dose concept in risk assessment. J Appl Toxicol. 2008;28:405-21.

23. Budtz-Jørgensen E, Keiding N, Grandjean P. Benchmark dose calculation from epidemiological data. Biometrics. 2001;57:698-706.

24. D’Agostino RB, Lee ML, Belanger AJ, Cupples LA, Anderson $\mathrm{K}$, Kannel WB. Relation of pooled logistic regression to time dependent Cox regression analysis: the Framingham Heart Study. Stat Med. 1990;9:1501-15.

25. Filipsson AF, Sand S, Nilsson J, Victorin K. The benchmark dose method - review of available models, and recommendations for application in health risk assessment. Crit Rev Toxicol. 2003;33:505-42.

26. Bøggild H, Burr H, Tüchsen F, Jeppesen HJ. Work environment of Danish shift and day workers. Scand J Work Environ Health. 2001;27(2):97-105.

27. Harada H, Suwazono Y, Sakata K, Okubo Y, Oishi M, Uetani $\mathrm{M}$, et al. Three-shift system increases job-related stress in Japanese workers. J Occup Health. 2005;47:397-404.

28. Grundy SM, Brewer HB Jr, Cleeman JI, Smith SC Jr, Lenfant C. Definition of metabolic syndrome: Report of the National Heart, Lung, and Blood Institute/American Heart Association conference on scientific issues related to definition. Circulation. 2004;109:433-8.

Received for publication: 13 October 2009 